Original Article

\title{
Relationship between the weight-bearing ratio on the affected lower extremity and gait ability using a portable electronic foot sensor shoe (Step $\left.\mathrm{Aid}^{\circledR}\right)$ in hemiplegic stroke patients
}

\author{
Keisuke Itotani, RPT ${ }^{1,6)^{*}}$, Masahito Murakami, RPT, PhD ${ }^{1)}$, Motoko Itotani, OTR ${ }^{2)}$, \\ Atsushi Nagai, RPT ${ }^{3)}$, Yuzo Imabori ${ }^{4)}$, Kazuyuki Fujimoto ${ }^{4)}$, Mamoru Tanaka ${ }^{4)}$, \\ Junichi KATO, MD, $\mathrm{PhD}^{5)}$ \\ 1) Department of Physical Therapy, Faculty of Rehabilitation, Kobe International University: 9-1-6 \\ Koyou-cho, Higashinada-ku, Kobe City, Hyogo 658-0032, Japan \\ 2) Department of Occupational Therapy, Faculty of Rehabilitation, Hyogo Prefectural Rehabilitation \\ Hospital at Nishi-Harima, Japan \\ 3) Department of Physical Therapy, Faculty of Rehabilitation, Hyogo Prefectural Rehabilitation \\ Hospital at Nishi-Harima, Japan \\ 4) IMAC Co., Ltd., Japan \\ 5) Internal Medicine, Hyogo Prefectural Rehabilitation Hospital at Nishi-Harima, Japan \\ 6) Kobe University Graduate School of Health Sciences Master's Program, Japan
}

\begin{abstract}
Purpose] This study investigated the association between the weight-bearing ratio (WBR) and gait ability of a paretic lower limb while walking using a shoe-type load-measuring apparatus. [Subjects] The Subjects comprised 17 stroke patients who were classified into the following two groups: the independent walking group, and the non-independent walking group. [Methods] The 10-m walking time (inside and outside parallel bars) and the Berg Balance Scale (BBS) were measured. The WBR of the paretic lower limb was measured during static standing and while walking inside and outside parallel bars, and the coefficient of variation (CV) was calculated. WBR was evaluated using the Step Aid. [Results] The BBS and WBR were significantly decreased in the non-independent walking group, while the $10-\mathrm{m}$ walking time and the $\mathrm{CV}$ were significantly increased in the non-independent walking group. [Conclusion] The CV and WBR of a paretic lower limb while walking appear to be important indices of achievement of independent gait in hemiplegic stroke patients, and they may be used in gait rehabilitation for diseases requiring weight-bearing training to follow the course of training using a shoe-type load-measuring apparatus.
\end{abstract}

Key words: Stroke, Weight-bearing ratio, Shoe-type load-measuring apparatus

(This article was submitted May 27, 2014, and was accepted Aug. 24, 2014)

\section{INTRODUCTION}

To improve the weight-bearing ratio (WBR) of a paretic lower limb while walking in hemiplegic stroke patients, it is important to perform gait training that takes motor and sensory disturbances and balance ability into account. Lower limb weight-bearing training using lower limb weight scales is conducted for paretic and non-paretic legs, but determination of whether the load is appropriate or insufficient is performed subjectively by instructors in many cases. Studies on paretic lower limb weight-bearing during static standing

*Corresponding author. Keisuke Itotani (E-mail: itotani@ kobe-kiu.ac.jp)

C 2015 The Society of Physical Therapy Science. Published by IPEC Inc. This is an open-access article distributed under the terms of the Creative Commons Attribution Non-Commercial No Derivatives (by-ncnd) License $<$ http://creativecommons.org/licenses/by-nc-nd/3.0/> . and gait ${ }^{1,2)}$ and measurement ${ }^{3)}$ of lower limb weight-bearing while walking after treatment for orthopedic diseases ${ }^{4)}$ have been reported.

A shoe-type load-measuring apparatus (product name: Step Aid, KKIMAC, Tokyo, Japan) was recently developed. It is equipped with an insole-type pressure load sensor and provides feedback through sound on whether lower limb weight-bearing while walking is appropriate, excessive, or insufficient.

In this study, the association between the WBR of a paretic lower limb and gait ability was investigated in hemiplegic stroke patients using this apparatus.

\section{SUBJECTS AND METHODS}

The subjects comprised 17 hemiplegic stroke patients who were admitted to our hospital for rehabilitation (mean age: $61 \pm 11$ years, 15 males and 2 females); 11 had cerebral infarctions, and 6 had cerebral bleeding. The grade of motor 
paralysis based on the Brunnstrom classification ${ }^{5)}$ was III, $\mathrm{IV}, \mathrm{V}$, and VI in $4,5,1$, and 7 patients, respectively, and the mean time to measurement from onset was $148 \pm 35$ days. Patients with severe higher brain dysfunction were excluded. The patients were divided into 2 groups as follows: 8 patients who could walk independently (using a cane and lower limb orthosis), and 9 patients who required assistance (using a wheelchair). The 10 -m walking time inside and outside parallel bars was measured, and the balance was evaluated using the Berg Balance Scale (BBS ${ }^{6}$ ). The WBR of the paretic lower limb was measured on static standing and while walking inside and outside parallel bars, and the coefficient of variation (CV) was calculated. The WBR of the paretic lower limb was measured during static standing held for 3 seconds. Paretic lower limb weight-bearing was evaluated by wearing a Step Aid $^{\circledR}$ (KKIMAC) on the paretic foot. The period from initiation to completion of the motion was measured, and the capture cycle was set at $10 \mathrm{~ms}$. The weight-bearing value was measured from the peak of each step. This apparatus is linked wirelessly to a measurement device through the pressure sensor built into the shoe insole, and it measures the load on each step. Sound signals are set for appropriate and under-load ranges, and feedback on the gait condition is provided so that the weight-bearing condition can be appropriately modified during training.

The items compared between the 2 groups were the $10-\mathrm{m}$ walking time inside and outside parallel bars, BBS, WBR of the paretic lower limb and its CV (\%) during static standing, 10-m gait inside and outside parallel bars, and the difference in the WBR between walking inside and outside parallel bars. The WBR (\%) was calculated as follows: (measured weight-bearing / body weight $) \times 100$. The CV (\%) was calculated as follows: standard deviation / average of the WBR during walking. The values are presented as means \pm standard deviation. The 2 groups were compared using the Student's t-test and Mann-Whitney's U test, and the significance level was set at less than 5\%. Statistical analysis was performed using Dr. SPSSII for Windows. Information about this study was provided in writing to all of the subjects prior to starting the study, and all subjects provided their informed consent. This study was performed following the regulations of the Clinical Study Committee of Hyogo Prefectural Rehabilitation Nishi-Harima Hospital.

\section{RESULTS}

The gait speeds and results of balance ability evaluation in the independent gait and gait-assisted groups of hemiplegic stroke patients are shown in Table 1 . The walking time was significantly shorter in the independent gait group than in the gait-assisted group inside and outside parallel bars (9.8 \pm 1.3 vs. $28.7 \pm 14.5$ seconds and $8.1 \pm 0.8$ vs. $34.9 \pm 28.1$ seconds, respectively; inside parallel bars, $\mathrm{p}<0.01$; outside parallel bars, $\mathrm{p}<0.05$ ), and the BBS score was significantly higher (53.2 \pm 2.6 vs. $40.2 \pm 6.4$, respectively; $p<0.001$ ).

The results for the WBR of the paretic lower limb in the independent gait and gait-assisted groups are shown in Table 2. The WBR of the paretic lower limb during static standing was significantly higher in the independent gait group $(97.7 \pm 2.5 \%$ vs. $71.3 \pm 12.1 \%$, respectively; $\mathrm{p}<0.001$ ),
Table 1. The 10-m gait time and balance ability evaluation in the independent gait and gait-assisted groups of the hemiplegic stroke patients

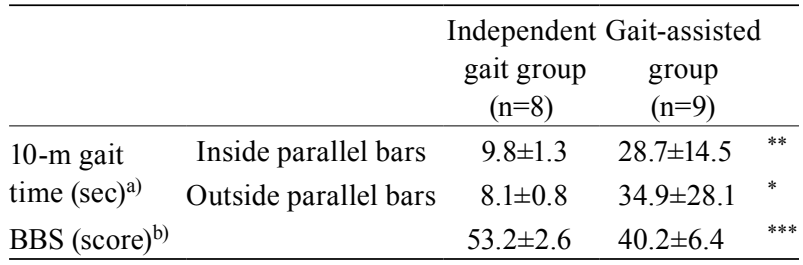

BBS: Berg Balance Scale

a) Mann-Whitney U test, ${ }^{\text {b) }}$ Student's t-test

Average \pm SD

${ }^{*}$ Statistically different at $\mathrm{p}<0.05,{ }^{* *}$ Statistically different at $\mathrm{p}<0.01,{ }^{* * *}$ Statistically different at $\mathrm{p}<0.001$

Table 2. Weight bearing ratio and coefficient of variation value of the paretic limb in the independent gait and gaitassisted groups of the hemiplegic stroke patients

\begin{tabular}{|c|c|c|c|c|}
\hline & & $\begin{array}{c}\text { Independent } \\
\text { gait group } \\
(\mathrm{n}=8)\end{array}$ & $\begin{array}{c}\text { Gait-assisted } \\
\text { group } \\
(\mathrm{n}=9)\end{array}$ & \\
\hline \multirow{3}{*}{$\begin{array}{l}\text { WBR } \\
(\%)\end{array}$} & Standing rest & $97.7 \pm 2.5$ & $71.3 \pm 12.1$ & \\
\hline & Gait inside parallel bars & $93.7 \pm 4.6$ & $85.9 \pm 11.2$ & ** \\
\hline & Gait outside parallel bars & $95.4 \pm 6.3$ & $85.1 \pm 9.1$ & ** \\
\hline $\mathrm{CV}$ & Gait inside parallel bars & $1.2 \pm 0.1$ & $1.6 \pm 0.6$ & \\
\hline$(\%)$ & Gait outside parallel bars & $1.1 \pm 0.1$ & $3.3 \pm 1.4$ & \\
\hline
\end{tabular}

WBR: weight bearing ratio, CV: coefficient of variation (standard deviation/average of WBR during walking), Student's ttest

Average \pm SD

${ }^{* *}$ Statistically different at $\mathrm{p}<0.01,{ }^{* * *}$ Statistically different at $\mathrm{p}<0.001$

and similar findings were obtained while walking inside and outside the parallel bars. Regarding the CV value, no significant difference was noted between the 2 groups in walking inside the parallel bars, but it was significantly higher in the gait-assisted group while walking outside the parallel bars $(1.1 \pm 0.1$ vs. $3.3 \pm 1.4$, respectively; $\mathrm{p}<0.001)$.

\section{DISCUSSION}

Since the ability to walk independently is the main factor determining whether patients with a cerebrovascular disorder accompanied by motor paralysis can return home ${ }^{7)}$, many studies on the WBR of paretic lower limbs have been reported; however, paretic lower limb weight-bearing during static standing was mainly investigated in clinical cases in previous studies ${ }^{1,2)}$. Recently, an insole load measurement apparatus equipped with a pressure sensor was developed, and measurement of weight-bearing on the sole during walking became possible. The Step Aid ${ }^{\circledR}$, used to evaluate lower limb weight-bearing, consists of a shoe with a built-in capacitance pressure sensor, and information on whether weight-bearing while walking is within an appropriate or underload region is fed back with sounds and lights. This apparatus is expected to be used for postoperative lower limb 
rehabilitation. This study focused on the WBR of the paretic lower limb in rehabilitation gait training in patients with cerebrovascular disorders accompanied by motor paralysis, and it investigated how the WBR of the paretic lower limb is involved in the independent gait of these patients using the Step Aid $^{\circledR}$.

It has occasionally been reported that paretic lower limb weight-bearing serves as an index to predict independent gait of patients with a cerebrovascular disorder accompanied by motor paralysis ${ }^{8,9)}$. In the present study, the WBRs of the paretic lower limbs during static standing and gait inside and outside parallel bars were significantly higher in the independent gait group than in the gait-assisted group, confirming that the WBR of the paretic lower limb is an important index concerning achievement of independent gait.

In addition, the CV value of the WBR of paretic lower limbs while walking outside the parallel bars was significantly higher in the gait-assisted group than in the independent gait group, showing the variation in paretic lower limb weight-bearing. The use of a cane to walk outside the parallel bars compensates for the support on the affected side and shifts the center of gravity of the body toward the affected side, which depends on the supportive function of the paretic lower limb. The BBS score was significantly lower in the gait-assisted group than in the independent gait group, suggesting that the balance function was poor and, thus, the supportive function was also reduced on the paretic side. Due to these factors, variation of the WBR of the paretic lower limbs may have increased significantly compared with that in the independent gait group. It appears that the BBS decreases as the WBR decreases, as well as vice versa.
In conclusion, the $\mathrm{CV}$ and the $\mathrm{WBR}$ on the paretic side while walking are important indices concerning achievement of independent gait in hemiplegic stroke patients, and follow-up of the course of lower limb WBR using the Step $\mathrm{Aid}^{\circledR}$ may be useful for gait rehabilitation in hemiplegic stroke patients and diseases requiring weight-bearing training after orthopedic treatment.

\section{REFERENCES}

1) Bohannon RW: Relationship among paretic knee extension strength, maximum weight-bearing, and gait speed in patients with stroke. J Stroke Cerebrovasc Dis, 1991, 1: 65-69. [CrossRef]

2) Femery VG, Moretto PG, Hespel JM, et al.: A real-time plantar pressure feedback device for foot unloading. Arch Phys Med Rehabil, 2004, 85: 1724-1728. [Medline] [CrossRef]

3) Tanaka S, Kubota K, Yoshimura O, et al.: Gait analysis after total knee arthroplasty - Comparison of cemented type and cementless type-. J Phys Ther Sci, 2000, 12: 101-105. [CrossRef]

4) Hustedt JW, Blizzard DJ, Baumgaertner MR, et al.: Current advances in training orthopaedic patients to comply with partial weight-bearing instructions. Yale J Biol Med, 2012, 85: 119-125. [Medline]

5) Brunnstrom S: Motor testing procedures in hemiplegia: based on sequential recovery stages. Phys Ther, 1966, 46: 357-375. [Medline]

6) Berg KO, Wood-Dauphinee SL, Gayton D: Measuring balance in the elderly: preliminary development of an instrument. Physiother Can, 1989, 41: 304-311. [CrossRef]

7) Marigold DS, Eng JJ: The relationship of asymmetric weight-bearing with postural sway and visual reliance in stroke. Gait Posture, 2006, 23: 249255. [Medline] [CrossRef]

8) Marthins EF, Ferreira PH, Barbosa A, et al.: Is it correct always consider weight-bearing asymmetrically distributed in individuals with hemiparesis? Physiotherapy Theory and Practice, Early online, 2011, 1-6.

9) Akezaki Y, Yamasaki H, Yoshimoto Y, et al.: The correlation between 6-mintes walk distance and weight bearing rate on the affected limb in cerebrovascular hemiplegic patients. Rigakuryoho Kagaku, 2009, 24: 41-44 (in Japanese). [CrossRef] 